\title{
EDITORIAL
}

\section{How much excess fluid impairs outcome of sepsis?}

\author{
Kelly R. Genga ${ }^{1}$ and James A. Russel1 ${ }^{1,2^{*}}$
}

(C) 2017 Springer-Verlag Berlin Heidelberg and ESICM

\section{Dear Editor,}

Fluid administration is fundamental in the treatment of sepsis and septic shock, but it is more difficult than a simple chemistry titration. Trials [1] and guidelines [2] recommend early and adequate fluid resuscitation in patients with sepsis and septic shock, as too little fluid may extend the duration of shock and organ ischemia, both important predictors of outcome. However, we [3] and others [4] have found associations between excess fluid administration and increased mortality due to septic shock, leading us to recommend a cautious approach to fluid resuscitation [5]. The definition of just how much fluid is adequate (or not) for good management of septic patients has been debated for years, and it is not yet clear precisely how much fluid is "excessive", thereby increasing the risk of mortality.

In a recent article in Intensive Care Medicine, Marik and colleagues [6] reported the results of their carefully designed cohort study of a large U.S. database (2013 Premier Hospital Discharge database; $n=23,513$ patients) in which they examined the relationships of fluid administration with outcomes (hospital mortality) of severe sepsis and septic shock. They also "assessed trends in the difference between actual and expected mortality in the low fluid range (1-5 L day one fluids) and the high fluid range (5-9+ L day one fluids)". The 5-L cut-off is interesting as it was defined by previously reported results [7] and confirmed very nicely by these authors. Day 1 fluid input averaged $4.4 \mathrm{~L}$ and was higher in patients who were ventilated and in shock than in patients without these diagnoses. Lower fluid volume (1-4.99 L) was associated

\footnotetext{
*Correspondence: Jim.Russell@hli.ubc.ca

${ }^{2}$ Division of Critical Care Medicine, St. Paul's Hospital, University of British Columbia, 1081 Burrard Street, Vancouver, BC V6Z 1Y6, Canada
}

Full author information is available at the end of the article with slightly lower mortality. Increasing fluid volume to $>5 \mathrm{~L}$ was associated with increased risk of death - an additional $2.3 \%$ for each extra liter exceeding $5 \mathrm{~L}$. In addition, the actual mortality exceeded the expected mortality for patients who received $>5 \mathrm{~L}$ of fluids on day 1 , particularly in those receiving $\geq 7 \mathrm{~L}$. This difference (actual vs. expected mortality) was found in patients who were (1) ventilated but not in shock, (2) in shock but not ventilated, and (3) ventilated and in shock (as demonstrated in Fig. 3 in the original paper).

The strengths of this cohort study are mainly the large sample size, across a wide range of U.S. hospitals, a priori defined fluid threshold, and the analytic approaches, (propensity matching of cases and controls, actual vs. expected mortality). Also (although this is a pragmatic cohort study), the authors evaluated the similarities between their study and important randomized controlled trials (RCTs) of early goal-directed therapy (EGDT) in the USA (PROCESS [8]), UK (PROMISE [9]), and Australia (ARISE [10]).

The greatest limitation of the study is that it is an association study, i.e., we can only speculate on causality. It is not surprising that patients in shock and/or on ventilation were sicker, needed more fluids, and had higher mortality. Thus, we are depending on the adequacy of the actual versus predicted mortality comparisons to suggest that fluid administration of $>5 \mathrm{~L}$ was associated with increased mortality in patients in shock and/or on ventilation. Another limitation is that day 1 was defined and calculated as a calendar day, not $24 \mathrm{~h}$. This would have impacted day 1 results, as the fluid-administered patients who had a 1-h day 1 are included in the same day 1 as patients who had a 23-h day 1 . Although the authors adjusted for this variation in the duration of day 1 by excluding patients who received less than $1 \mathrm{~L}$, this may not be an adequate adjustment.

\section{实


This study is reminiscent of the one conducted by Kumar et al. which showed associations of delays in antibiotics and increased mortality of septic shock [11], leading to strong recommendations for early (within $1 \mathrm{~h}$ ) antibiotic treatment of patients in septic shock [2]. However, while there will likely not be RCTs of early versus delayed antibiotics for ethical reasons, there are now at least four trials of EGDT [1, 8-10] versus usual care. The "post-Rivers" RCTs show no difference between EGDT and usual care has led to interpretations that usual care (that limited fluids compared to EGDT) is supported by meta-analyses [12] and is now preferred [13].

Although the results reported by Marik and colleagues [6] seem to align with those of these RCTs and metaanalyses, it must be stated that EGDT is a complex and multi-dimensional intervention that includes fluids, vasopressors, inotropic agents, and red blood cell transfusion, guided by central venous oxygen saturation. Thus, we are left with an ongoing gap in evidence regarding a "safe" upper limit of fluids in sepsis. Furthermore, the 5 L cut-off is derived from a specific group of patients, without consideration being given to the wide variation of the individual patient's fluid requirements. The latter is another compelling reason why, in our opinion, it is quite improbable that we find a "safe" upper cut-off for fluid volume administration that can be applied to individual patients.

The clinical take-home message from the paper (not entirely novel or unexpected) is that optimal fluid resuscitation is a truly important factor in shock and in acute respiratory failure. The authors found striking mortality effects in patients who received high volume resuscitation and mechanical ventilation (regardless if shock was present) and in patients who received low-volume resuscitation and had shock but were not mechanically ventilated (perhaps representing "under-resuscitated" patients). Additionally, the $U$ shape of actual mortality (i.e., higher mortality in patients administered low- and high-volume fluids) in patients (1) with shock but without ventilation and (2) without shock but with ventilation is noteworthy. One reason for these findings is that patients presenting with respiratory failure and/or shock have more pronounced "dysregulated host response to infection" (as per sepsis definition) [14]. Consequently, they may more frequently have excessive vasodilatation and vascular hyporesponsiveness [15], mitochondrial dysfunction [16], global myocardial depression [16], and increased vascular permeability [17]. Therefore, there are penalties for under- and over-resuscitating leading to an increased risk of organ ischemia/hypoxia and organ edema, respectively [5] (Fig. 1).

In summary, Marik and colleagues [6] have conducted a very nice cohort study of a large representative sample of the U.S. critically ill population, with the results suggesting that fluid administration which is inadequate or excessive is potentially harmful [5] in sepsis and septic shock. However, the statement that there is a "magical number" $-5 \mathrm{~L}$-representing a threshold

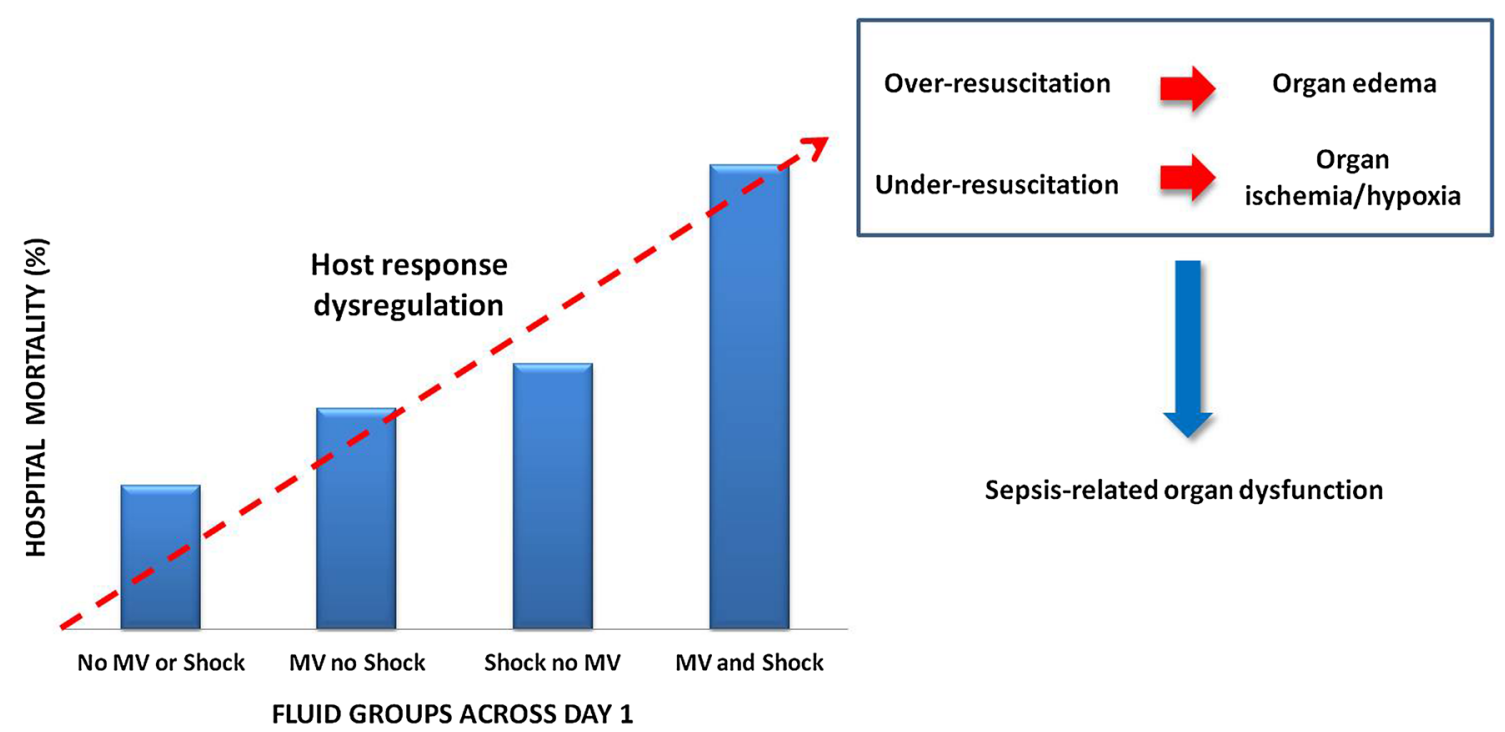

Fig. 1 Hospital mortality according to patient groups of (1) no MV or shock, (2) MV but no shock, (3) shock but no MV, and (4) MV and shock. Sicker patients have a greater dysregulated host response to infection and increased mortality, in part because the sickest patients commonly suffer the penalties for under- and over- resuscitation, i.e. organ ischemia/hypoxia and organ edema, respectively, thereby increasing the risk of sepsis-related organ dysfunction. MV Mechanical ventilation 
of over-resuscitation risk in sepsis is questionable. The argument would be more cogent if these results were validated in independent large cohorts from other countries or regions.

\section{Author details}

${ }^{1}$ Centre for Heart Lung Innovation (HLI), St. Paul's Hospital, University of British Columbia, 1081 Burrard Street, Vancouver, BC V6Z 1Y6, Canada. ${ }^{2}$ Division of Critical Care Medicine, St. Paul's Hospital, University of British Columbia, 1081 Burrard Street, Vancouver, BC V6Z 1Y6, Canada.

Received: 17 January 2017 Accepted: 25 February 2017 Published online: 27 March 2017

\section{References}

1. Rivers E, Nguyen B, Havstad S, Ressler J, Muzzin A, Knoblich B et al. (2001) Early goal-directed therapy in the treatment of severe sepsis and septic shock. N Engl J Med 345(19):1368-1377

2. Dellinger RP, Levy MM, Rhodes A, Annane D, Gerlach H, Opal SM et al. (2013) Surviving Sepsis Campaign: international guidelines for management of severe sepsis and septic shock, 2012. Intensive Care Med 39(2):165-228

3. Boyd JH, Forbes J, Nakada TA, Walley KR, Russell JA (2011) Fluid resuscitation in septic shock: a positive fluid balance and elevated central venous pressure are associated with increased mortality. Crit Care Med 39(2):259-265

4. Murphy CV, Schramm GE, Doherty JA, Reichley RM, Gajic O, Afessa B et al. (2009) The importance of fluid management in acute lung injury secondary to septic shock. Chest 136(1):102-109

5. Genga K, Russell JA (2016) Early liberal fluids for sepsis patients are harmful. Crit Care Med 44(12):2258-2262

6. Marik PE, Linde-Zwirble WT, Bittner EA, Sahatjian J, Hansell D (2017) Fluid administration in severe sepsis and septic shock, patterns and outcomes: an analysis of a large national database. Intensive Care Med. doi:10.1007/ s00134-016-4675-y
7. Smith SH, Perner A (2012) Higher vs. lower fluid volume for septic shock: clinical characteristics and outcome in unselected patients in a prospective, multicenter cohort. Crit Care 16(3):R76

8. Yealy DM, Kellum JA, Huang DT, Barnato AE, Weissfeld LA, Pike F et al. (2014) A randomized trial of protocol-based care for early septic shock. N Engl J Med 370(18):1683-1693

9. Mouncey PR, Osborn TM, Power GS, Harrison DA, Sadique MZ, Grieve RD et al. (2015) Trial of early, goal-directed resuscitation for septic shock. N Engl J Med 372(14):1301-1311

10. Peake SL, Delaney A, Bailey M, Bellomo R, Cameron PA, Cooper DJ et al. (2014) Goal-directed resuscitation for patients with early septic shock. N Engl J Med 371(16):1496-1506

11. Kumar A, Roberts D, Wood KE, Light B, Parrillo JE, Sharma S et al. (2006) Duration of hypotension before initiation of effective antimicrobial therapy is the critical determinant of survival in human septic shock. Crit Care Med 34(6):1589-1596

12. Angus DC, Barnato AE, Bell D, Bellomo R, Chong CR, Coats TJ et al. (2015) A systematic review and meta-analysis of early goal-directed therapy for septic shock: the ARISE. ProCESS and ProMISe Investigators, Intensive care medicine. doi:10.1007/s00134-015-3822-1

13. Russell JA, Moller MH, Annane D (2015) Early goal-directed therapy: from discovery through enthusiasm to equipoise? Intensive Care Med 41:1676-1678

14. Singer M, Deutschman CS, Seymour CW, Shankar-Hari M, Annane D, Bauer $M$ et al. (2016) The third international consensus definitions for sepsis and septic shock (Sepsis-3). JAMA 315(8):801-810

15. Levy B, Collin S, Sennoun N, Ducroca N, Kimmoun A, Asfar P et al. (2010) Vascular hyporesponsiveness to vasopressors in septic shock: from bench to bedside. Intensive Care Med 36(12):2019-2029

16. Antonucci E, Fiaccadori E, Donadello K, Taccone FS, Franchi F, Scolletta S (2014) Myocardial depression in sepsis: from pathogenesis to clinica manifestations and treatment. J Crit Care 29(4):500-511

17. Lee WL, Slutsky AS (2010) Sepsis and endothelial permeability. N Engl J Med 363(7):689-691 